\title{
Accessibility Matters: Universal Design and the Online Professional Practice Doctorate
}

\author{
Lindsey A. Chapman \\ University of Florida \\ l.chapman@coe.ufl.edu \\ Amanda M. Jackson \\ University of Florida \\ ajackson@ufsa.ufl.edu
}

\begin{abstract}
Online doctoral programming geared toward working professionals can provide unprecedented flexibility in terms of time and place that affords greater access to a broader student demographic. At the same time, online learning poses its own unique set of challenges and limitations for students with and without disabilities. Universal Design (UD) is a framework built around the idea of proactively identifying and removing barriers to learning in the environment, pedagogical practices, and materials. In this essay, we highlight the necessity and relevance of UD to online doctoral programs and share insights related to its use in our program from faculty and student perspectives.

\section{KEYWORDS}

universal design, accessibility, online programs, special education
\end{abstract}

Recent technological and pedagogical advances in online learning allowed for programmatic development that might not have been imagined, nor possible, a century ago. The advent of the online education doctorate (Ed.D.) and efforts from the Carnegie Project for the Educational Doctorate (CPED) have helped (re)imagine what it means to provide rigorous and high-quality doctoral level preparation that is grounded in professional practice. Online doctoral programming geared toward working professionals can provide unprecedented flexibility in terms of time (i.e., asynchronous learning opportunities) and place (i.e., geographic location) that affords greater access to a broader student demographic (Roddy et al., 2017). Experienced educational leaders seeking online doctoral programs tend to be older and/or with greater personal and professional commitments than their on-campus counterparts (Johnson, 2015; Kahu et al., 2013), so this level of flexibility is desirable and often essential.

At the same time, online learning poses its own unique set of challenges and limitations. Some online practices erect significant barriers for students, especially those with disabilities (Burgstahler, 2015) and/or from other historically marginalized and minoritized groups (Duquaine-Watson, 2008). In this way, Universal Design (UD) is critically important in online programs. UD supports the critical examination of instructional delivery methods, the virtual learning environment, content material and technology tool selection, and opportunities for student support that have been integral to our development and improvement efforts. It encourages proactive planning with intentional reflection based around the anticipation and recognition of barriers present in the learning process and environment rather than within students (Center for Applied

New articles in this journal are licensed under a Creative Commons Attribution 4.0 United States License.
Technology [CAST], 2011). Instead of maintaining and promoting deficit perspectives of students in traditional education spaces, UD builds on and embraces students' diverse backgrounds, experiences, and needs (Rogers-Shaw et al., 2018).

We contend that UD is a necessary, yet often overlooked element in online programming. In this essay, we share successes, challenges, and future possibilities related to the use of UD in our online Ed.D. program. We first offer a brief history of UD and its origins beyond the educational space. We then outline the guidelines and principles of two prominent UD models as well as situating their need through examination of the barriers specific to online learning in higher education. Then, we draw from our differing lenses and positionalities as program faculty/Ed.D. coordinator and Ed.D. student in sharing insight on the use of UD in the design, implementation, and evaluation processes of our program. We conclude with a call to action for other online doctoral programs preparing educational stakeholders across disciplines.

\section{UNIVERSAL DESIGN}

Ronald Mace, an architect who is widely credited for his contribution to the popularization of UD, defined the concept as a "commonsense approach to making everything we design and produce usable by everyone to the greatest extent possible" (Roberts et al., 2011, p. 6). Mace and others initially focused on the creation of accessible physical environments which included the development of curb cuts for wheelchair accessibility and later closed captioning on television programs for the Deaf community

This journal is supported by the Carnegie Project on the Education Doctorate: A Knowledge Forum on the EdD (CPED) cpedinitiative.org 


\begin{tabular}{|c|c|c|c|}
\hline Framework & Pri & iples & \\
\hline \multirow{12}{*}{$\begin{array}{l}\text { Universal Design for Learning } \\
\text { (CAST, 2011) }\end{array}$} & \multirow[t]{4}{*}{1.} & \multicolumn{2}{|c|}{ Provide multiple means of representation } \\
\hline & & a. & Provide options for perception \\
\hline & & b. & Provide options for language and symbols \\
\hline & & c. & Provide options for comprehension \\
\hline & 2. & \multicolumn{2}{|c|}{ Provide multiple means of action and expression } \\
\hline & & a. & Provide options for physical action \\
\hline & & b. & Provide options for expression and communication \\
\hline & & & Provide options for executive function \\
\hline & \multirow[t]{4}{*}{3.} & \multicolumn{2}{|c|}{ Provide multiple means of engagement } \\
\hline & & a. & Provide options for recruiting interest \\
\hline & & b. & Provide options for sustaining effort and persistence \\
\hline & & c. & Provide options for self-regulation \\
\hline \multirow{8}{*}{$\begin{array}{l}\text { Universal Instructional Design } \\
\text { (Higbee, 2009) }\end{array}$} & 1. & \multicolumn{2}{|c|}{ Creating welcoming classrooms } \\
\hline & 2. & \multicolumn{2}{|c|}{ Determining essential components of a course } \\
\hline & 3. & \multicolumn{2}{|c|}{ Exploring use of natural supports for learning } \\
\hline & 4. & \multicolumn{2}{|r|}{$\begin{array}{l}\text { Designing teaching methods that consider diverse learning modalities, } \\
\text { abilities, ways of knowing, and previous experience }\end{array}$} \\
\hline & 5. & \multicolumn{2}{|c|}{ Communicating clear expectations } \\
\hline & 6. & \multicolumn{2}{|c|}{ Promoting interaction between faculty and students } \\
\hline & 7. & \multicolumn{2}{|c|}{ Providing timely and constructive feedback } \\
\hline & 8. & \multicolumn{2}{|r|}{ Creating multiple ways for students to demonstrate knowledge } \\
\hline
\end{tabular}

Table 1. Principles of prominent UD frameworks

(Jimenez et al., 2007). During the 1970s, the concept of UD moved beyond the removal of physical barriers for people with disabilities to emphasize integration of all people across all settings and environments (Roberts et al., 2011).

In recent decades, the concept of UD has been expanded for PK-20 educational environments through the development of adapted frameworks such as Universal Design for Learning (UDL; Rose \& Meyer, 2000) and Universal Instructional Design (UID; Higbee, 2009) whose principles are highlighted in Table 1.

While there are nuanced differences across the two models, each operates under the recognition that the structures and "disabled curriculum" (Rappolt-Schlichtmann et al., 2012) commonly utilized within educational environments create barriers to learning for students with and without disabilities. Therefore, these UD approaches emphasize universal accessibility to learning by "reorient[ing] how knowledge is defined, obtained, and expressed" (Rogers-Shaw et al., 2018, p. 21). In online contexts, UD can be strategically interwoven into every aspect of programming (i.e., design, implementation, and evaluation) to meet a wide variety of student needs and learning preferences while simultaneously leveraging their existing knowledge and strengths.

Popularized by the Center for Applied Special Technology (CAST), UDL is widely known and utilized, especially in K-12 educational contexts. Rather than a single practice or method, UDL is a framework based around the what, how, and why of learning. According to CAST (2011), its three principles guide educators to provide multiple means of 1 ) representation (i.e., what learners access to gain understanding or information), 2) action and expression (i.e., how learners demonstrate their understanding of the content), and 3) engagement (i.e., why the learner engages in the learning process). Educators are also encouraged to team these principles with a backwards design process that first considers clear and measurable outcomes before identifying potential barriers that need to be addressed (Smith \& Basham, 2014).

Though UDL can be applicable across educational settings, UID is an extension of UDL, providing explicit guidance for higher education contexts (Rao, 2013). According to Higbee (2009), UID has eight guiding principles that are rooted in physical presence, effective and efficient communication, diverse teaching methods and assessment measures, and collaboration amongst others. It provides specific, alternative approaches to traditional educational practices that marginalize non-traditional students in all learning environments, including online and virtual spaces (Rao \& Tanner, 2011). The UDL and UID frameworks are complementary rather than contradictory. Both emphasize a process of anticipating barriers and learning needs, developing targeted assessment and the instructional experience, and finally, fostering ongoing opportunities for critical reflection (Smith \& Basham, 2014).

\section{Barriers in Online Learning}

With the increased demand for online learning, there needs to be broader recognition of the issues unique to this type of instructional delivery. Generally speaking, online learning may pose barriers for students caused by ambiguity and/or uncertainty about expectations, overreliance on text-based learning modalities, isolation and lack of community, and technology challenges (Rao, 2013). Palmer and Caputo (2003) offered several guiding questions that can support the identification of these types of barriers in online courses such as:

1) Are there major areas of confusion or inconsistency among course objectives, your own expectations, and/ or how the course is presented?, 2) Does the course offer enough choice 
so that students can, to a reasonable extent, demonstrate their competency in a way that suits their needs and abilities?, 3) Might students have any difficulties accessing course materials or participating in any essential activities related to this class?, and 4) Is some information in the course presented exclusively in a format that might be inaccessible to some students? (p. 13)

Barriers in online learning may affect all students but are also likely intensified for some groups. For example, students from historically marginalized racial, ethnic, and/or socioeconomic backgrounds are more likely to have limited access to digital resources and be affected by the digital divide while being susceptible to greater feelings of isolation from their peers (Duquaine-Watson, 2008). Students with disabilities may also experience greater barriers in online environments. This is especially true when there are uncaptioned videos, images without alternative text, or information is provided in disorganized and uncategorized formats (Burgstahler, 2015). Once identified, the guidelines and principles of UD are intended to support educators in removing barriers for all students across all aspects of a program (i.e., design, implementation, and evaluation; see Table 2).

\begin{tabular}{|c|c|c|c|}
\hline Potential Barrier & $\begin{array}{l}\text { Example of UD Applied to } \\
\text { Program and Course Design }\end{array}$ & $\begin{array}{l}\text { Example of UD Applied to } \\
\text { Implementation }\end{array}$ & $\begin{array}{l}\text { Example of UD Applied to } \\
\text { Evaluation }\end{array}$ \\
\hline $\begin{array}{l}\text { Ambiguity and uncertainty of } \\
\text { expectations }\end{array}$ & $\begin{array}{l}\text { Build consistent and organized } \\
\text { LMS sites }\end{array}$ & $\begin{array}{l}\text { Encourage students to } \\
\text { communicate needs and } \\
\text { preferences }\end{array}$ & $\begin{array}{l}\text { Establish and modify goal setting } \\
\text { and evaluation throughout the } \\
\text { program }\end{array}$ \\
\hline $\begin{array}{l}\text { Excessive reliance on text- } \\
\text { based learning and } \\
\text { assessment }\end{array}$ & $\begin{array}{l}\text { Design a variety of assessment } \\
\text { formats (presentations, papers, } \\
\text { videos, group work) aligned to } \\
\text { course objectives and goals }\end{array}$ & $\begin{array}{l}\text { Provide multimodal course } \\
\text { materials and assignments that } \\
\text { are scaffolded and organized on } \\
\text { the LMS }\end{array}$ & $\begin{array}{l}\text { Utilize course mid-semester and } \\
\text { end of the semester evaluations } \\
\text { that assess for accessibility of } \\
\text { materials and assignments }\end{array}$ \\
\hline $\begin{array}{l}\text { Isolation and lack of } \\
\text { community }\end{array}$ & $\begin{array}{l}\text { Establish program cohorts while } \\
\text { providing multiple outlets of } \\
\text { connection }\end{array}$ & $\begin{array}{l}\text { Provide opportunities for } \\
\text { synchronous and asynchronous } \\
\text { learning to increase peer } \\
\text { communication and engagement }\end{array}$ & $\begin{array}{l}\text { Review communication with } \\
\text { students and amongst students } \\
\text { to increase availability and } \\
\text { formal/informal participation }\end{array}$ \\
\hline $\begin{array}{l}\text { Relevance to professional } \\
\text { roles/ context }\end{array}$ & $\begin{array}{l}\text { Establish course content that } \\
\text { connects relevance and value to } \\
\text { practical, real-world applications } \\
\text { and problem solving across } \\
\text { professional contexts }\end{array}$ & $\begin{array}{l}\text { Provide choices for students in } \\
\text { terms of topics, readings, and } \\
\text { other assignment tasks }\end{array}$ & $\begin{array}{l}\text { Adjust courses and assignments } \\
\text { regularly to account for changes } \\
\text { in students' professional } \\
\text { contexts and roles }\end{array}$ \\
\hline
\end{tabular}

Table 2. Examples of practices that support UD in the online professional practice doctorate

\section{UNIVERSAL DESIGN AND ONLINE PROFESSIONAL PRACTICE DOCTORATE PROGRAMS}

The online Doctor of Education (Ed.D.) in Special Education program at the University of Florida is a professional practice doctorate program designed to develop scholarly practitioners who can serve as advocates for individuals with disabilities within schools and the community. In many ways, the decision to develop an online Ed.D. was uncharted, and necessary, territory for our faculty. Its first group of students began in 2018 and was built around the principles and guidance of the CPED framework. Consistent with the broader trends of online learners in graduate education programs, our students are full-time working professionals. They support students with disabilities in varied capacities across the spectrum of PK-20 education and bring diverse experiences and identities into the program.

We share in Rogers-Shaw et al.'s (2018) assertion that, "to teach, to learn, to develop programs and curricula is to engage, develop, and appreciate, not simply the content and learning objectives themselves, but also, primarily, the interaction of learners unique histories, abilities, cultures, and characteristics" (p. 23). As faculty in online programs, we need to think carefully not just about our program goals and coursework, but about our students. This means building on their rich practical knowledge and experience as educational leaders and emerging scholarly practitioners in their doctoral journeys. It also means recognizing that our students are balancing varied personal and professional responsibilities and the educational demands of doctoral study in an online environment. Thus, the principles of UD guide our faculty in the identification and removal of barriers to their learning. We use our respective lenses, one author as program faculty and the other as a student, to share our perspectives on the embeddedness of UD into the design and development, implementation, and evaluation of our program in the following sections.

\section{Design and Development}

Some of the most critical features of UD (e.g., development of clear and measurable outcomes) are standard development practices in online graduate education programs, especially in those influenced by the CPED framework. The design process for our online Ed.D. program involved the development of a competency matrix based on guidance from CPED and professional organizations in the field of special education. This matrix helped structure the student outcomes that were then mapped onto our respective courses, with key assessments and advising/mentoring structures serving as important checkpoints in students' progression through the program. While the general structure has remained the same in the three years since our program began, it has been updated and adapted to reflect changes in the population and number of students we serve. 
There are two main considerations for online course design and development: a) technology (e.g., Learning Management Systems [LMS], video conferencing platforms) and b) pedagogy (e.g., instructional materials and strategies) that can be informed by UD (Rao \& Tanners, 2011). Our courses are housed in the Canvas LMS and organized into easily navigable modules that include clearly identifiable objectives and goals, materials (e.g., texts, videos, links, audio files), assignments, and multimodal spaces for dialogue and collaboration. They are designed to utilize both synchronous and asynchronous approaches to instructional delivery by capitalizing on the integration of external platforms like Zoom and Perusall into Canvas. Student cohorts also have access to a group advising shell in their Canvas sites to make program related documents, updates, and announcements easily accessible while contained within one system.

\section{Student Perspective}

Starting a doctoral journey while being a working professional with several competing responsibilities felt challenging for me at first. Faculty who provided clear expectations during the first week of class helped to alleviate my anxiety of how time should be prioritized. The syllabus is by far one of the most important components for students because it allowed me to proactively review the requirements of the assignments and develop a plan of action for managing newfound responsibilities. I also found the syllabus to be a starting point for the foundation of an inclusive environment that made me more comfortable in my new learning space. For example, several courses in our program included an accessibility statement (see Figure 1) on the syllabus which set the tone for a course that would be supportive of different learning preferences and professional goals. Seeing the structure of the syllabus complemented in a well-organized Canvas shell was also essential. It allowed me the structure I needed to focus on course content without additional difficulties in navigating the online environment.

\begin{abstract}
Accessibility
I am committed to creating a course that is inclusive in its design. If you encounter barriers, please let me know immediately so that we can determine if there is a design adjustment that can be made or if an accommodation might be needed from the Disability Resource Center to overcome the limitations of the design. I am always happy to consider creative solutions as long as they do not compromise the intent of the assessment or learning activity. I welcome feedback that will assist me in improving the usability and experience for all students.
\end{abstract}

Figure 1. Example of an accessibility statement from a course syllabus

Additionally, it was also evident to me as a student that program faculty carefully selected texts and course materials that could be tailored to students' individual educational environments which encouraged sustained effort and interest in progressing through the program. As each course built upon the other, the courses did not feel disjointed or unattached to the end goal of the doctoral journey, our dissertation in practice. Moreover, I was encouraged to take ownership, autonomy, and creativity in determining the direction of my doctoral program to meet my personal professional goals. This is particularly important in our program given the wide variety of professional contexts represented by our students.

\section{Implementation}

Burgstahler (2015) advocated for a universally designed online course that will allow students to utilize their preferred method of engagement and expression in order to combat the potential inaccessible features or design elements. Students are encouraged to engage with a wide array of multimodal learning materials beyond traditional academic text and to use a multitude of formats and platforms in completing their assignments. For example, video and audio formats are increasingly being used to foster dialogue between both faculty and students in course discussion forums asynchronously. It is worth noting that platforms like Zoom and YouTube can auto-generate captions and/or transcripts for these videos and media, providing additional options for how information can be consumed by peers and faculty. Further, many of our courses are also built around semester long projects that are chunked into manageable sections and due at various stages of the semester to check for understanding (CAST, 2011). In these tasks, students are given opportunities to translate and contextualize course content into their professional settings in addition to frequent and timely feedback in that process.

One lingering challenge we have faced in terms of implementation has been varying degrees of preparedness among our program faculty for online teaching generally, and UD embedded online teaching specifically. While there is vast familiarity with the concept of UD, translating these principles into digital, higher education spaces has come with its own set of difficulties. The proactive nature of UD makes the process of implementation nonlinear; while some barriers can easily be anticipated, others cannot. Implementation also requires an iterative process of trial and error that takes time and continued professional learning. As a relatively new program with faculty of mixed levels of experience in teaching doctoral level courses online, we are still working on facilitating this process more consistently across the program. We have begun to foster collaborative systems, like course shadowing, whereby faculty can learn from one another by experiencing UD implemented in other program courses. However, more opportunities for education and development are needed and planned in the coming years.

\section{Student Perspective}

Engaging within a learning environment after potentially spending years in the work environment can require students to go through a huge learning curve due to changes in technology and instructional methods. From the student perspective, what stood out most in implementation was faculty who paid close attention to their instructor presence in the course. This was done through providing video feedback with transcripts on discussion board posting and assignments which built in the face-to-face component in an online learning environment. Providing students with timely feedback on semester long projects chunked into smaller assignments allowed me to apply the feedback, thus improving my skills throughout the course. Likewise, feedback focused on the growth of the scholarly practitioner versus the letter grade, allowing me the freedom to experience the iterative process of problem-solving and inquiry. Additionally, faculty were consistently cognizant of the importance of applicability to content and time commitments which greatly impacted the student experience.

Faculty also allowed flexibility and choice making when scheduling synchronous learning experiences and office hours due to students balancing multiple personal and professional commitments. By providing this flexibility in scheduling, I had easy access to my faculty for guidance, mentorship, and feedback. Synchronous meetings each semester for each cohort of students 
served as a space for students to vocalize feedback about their courses, provide an update on the cohort's progression in the program, and offer easily implementable skills, such as building a professional social media network. These meetings increased morale and the feeling of community amongst students, an important feature of online programming.

\section{Evaluation}

Smith and Basham (2014) provided the following questions to guide the processes of critical reflection and improvement based on UD models:

- Were outcomes as planned? Did all learners meet desired high-expectations?

- What data support your inference?

- What instructional strategies worked well?

- How could the use of instructional strategies be improved?

- What tools worked well? How could the use of tools be improved?

Students and program faculty have multiple opportunities for both formal and informal feedback, dialogue, and reflection within and beyond their respective courses. These data provide useful insight for reflecting on the ways in which our program design and implementation are successful in removing barriers for students. In evaluating formal and informal feedback on our program and courses, we noticed a trend consistent with other literature on UD in higher education (i.e., Rao, 2013). Students have had more favorable evaluations and responses to the courses that most strongly align and incorporate the principles of UD.

The evaluation process can also inform improvement. Our program was not initially designed to utilize a cohort structure; instead, we used a rolling admissions process whereby students were admitted to the program each semester during the first two years of the program. What we had initially thought of as increased flexibility for students had instead created additional barriers to student success that we had to address. Applying the principles of UD into this process allowed us to develop a structured and sequential program plan while maintaining consideration of student interest and decision-making related to coursework. Because it was important to our faculty to maintain some aspect of flexibility and student choice related to coursework, we embedded 12 credits for student-selected specialization coursework (e.g., dyslexia, professional development, disability in society), but structured these opportunities into the course sequence. These courses were paired with students' foundational courses through the first four semesters of study. Reviewing and addressing the program structure allowed for more intentionality in terms of how students' background knowledge was supplemented through each course.

\section{Student Perspective}

As a student, it was evident to me that the program faculty was consistently finding ways to improve students' experience both within and beyond individual courses. Through listening to the voices of students, faculty would adjust and respond. For example, I collaboratively led and faculty-supported our effort to foster informal communication avenues through Microsoft Teams, virtual social gatherings, and a peer accountability system that had not previously been part of the program design. These informal, student-centered spaces provided opportunities for relationship and community building within and across cohorts. In an online learning environment, I felt disconnected to my peers and faculty; however, efforts to increase collaborative learning through formal instructional methods and informal student-led initiatives in response to our feedback helped strengthen the accessibility of our program.

\section{A CALL TO ACTION}

The advent of online programs has enabled greater access to doctoral study for working professionals without the traditional constraints associated with time and location. In many ways, online programs, especially those guided by the CPED framework, have pushed the boundaries of doctoral study in a way that would have been impossible a century or even decades ago. Yet these changes necessitate intentional shifts in practice that center and prioritize accessibility for students. As asserted by Jiménez et al. (2007), "we cannot expect teachers and school professionals to change the way they provide instruction and collaborate without expecting universities to change the way they prepare educational professionals infield" (p. 51). In using UD as a means of changing the way we prepare our students, we have learned that it is imperative to listen to and center student voices in programmatic decision-making. We have also learned that we need to remain positioned for growth as new barriers emerge from changing contexts and circumstances within our institution and beyond.

So, where do we go from here? As a program, we continue to grapple with how to further our quest for a more socially just and equity-oriented educational environment. We will persist in providing opportunities for faculty collaboration and development, eliciting feedback from students, and looking to CPED for continued guidance. In the coming years, we plan to focus these efforts on the critical evaluation of our major program milestones (e.g., qualifying examinations, dissertation-in-practice) with UD in mind in order to push the boundaries of what constitutes knowledge and how it is represented. We also hope to engage with other Ed.D. programs across disciplines around issues of equity and how this idea can be operationalized with accessibility at the forefront. We move forward in these pursuits guided by the assertion by Perry and colleagues (2020) that "Change in higher education is incredibly difficult, but it is doable" (p. 5).

As a program focused on preparing educational professionals to support students with disabilities, embodying the guidelines and principles of UD is also an essential means of 'practicing what we teach and preach'. But its importance is not limited to special education programs. Given the unique complexities and barriers inherent in online learning, UD can and should be an integral part of the online professional practice doctorate across disciplines. We hope that this essay inspires our colleagues to focus on accessibility and opportunities to utilize UD; but, start small. This may mean working together to identify potential barriers in the context of your program and discipline, carefully examine the UD principles, and assess the extent to which they may already be evident in varied aspects of your program. From there, consider focusing on a single course or a specific UD principle as an incremental next step. These efforts can be scaled up over time in tandem with ongoing feedback from students. It may not be easy, but it will be worth it. Utilizing UD helps us in our shared goal of reimagining the how, why, and what of doctoral study without compromising the rigor and relevance 
necessary to prepare scholarly practitioners who are agents of change in their professional practice.

\section{AUTHOR NOTE}

We have no known conflict of interest to disclose.

Correspondence concerning this article should be addressed to Lindsey A. Chapman, School of Special Education, School Psychology, and Early Childhood Studies, University of Florida, Email: I.chapman@coe.ufl.edu.

\section{REFERENCES}

Burgstahler, S. (2015). Opening doors or slamming them shut? Online learning practices and students with disabilities. Social Inclusion, 3(6), 69-79. https://doi.org/10.17645/si.v3i6.420

Center for Applied Technology. (2011). Universal Design for Learning guidelines version 2.0. http://www.cast.org

Duquaine-Watson, J. M. (2008). Computing technologies, the digital divide, and "Universal" instructional Methods. In J. L. Higbee \& E. Goff (Eds.) Pedagogy and student services in institutional transformation: Implementing Universal Design in higher education (pp. 437-449) University of Minnesota Center for Research on Developmental Education and Urban Literacy. https://www.cehd.umn.edu/passit/docs/ PASS-IT-Book.pdf

Higbee, J. L. (2009). Implementing universal instructional design in postsecondary courses and curricula. Journal of College Teaching \& Learning, 6(8), 65-77. https://doi.org/10.19030/tlc.v6i8.1116

Jimenez, T. C., Graf, V. L., \& Rose, E. (2007). Gaining access to general education: The promise of Universal Design for Learning. Issues in Teacher Education, 16(2), 41-54. https://eric.ed.gov/?id=EJ796250

Johnson, G. M. (2015). On-campus and fully-online university students: Comparing demographics, digital technology use and learning characteristics. Journal of University Teaching \& Learning Practice, 12(1). https://ro.uow.edu.au/jutlp/vol12/iss1/4

Kahu, E. R., Stephens, C., Leach, L., \& Zepke, N. (2013). The engagement of mature distance students. Higher Education Research \& Development, 32(5), 791-804. https://doi.org/10.1080/07294360.2013.777036

Palmer, J. \& Caputo, A. (2003). The Universal Instructional Design implementation guide. https://cer.jhu.edu/files/uid-implementation-guide-v6.pdf

Perry, J. A., Zambo, D., \& Abruzzo, E. (2020). Faculty leaders challenges and strategies in redesigning EdD programs. Impacting Education: Journal on Transforming Professional Practice, 5(1), 1-6. https://doi.org/10.5195/ie.2020.143

Rao, K. (2013). Universal instructional design of online courses: Strategies to support non-traditional learners in postsecondary environments. In S. Burgstahler (Ed.). Universal design in higher education: promising practices. http://www.uw.edu/doit/UDHEpromising-practices/uid_online. html

Rao, K., \& Tanners, A. (2011). Curb cuts in cyberspace: Universal Instructional Design for online courses. Journal of Postsecondary Education and Disability, 24(3), 211-229. https://eric.ed.gov/?id=EJ966125

Rappolt-Schlichtmann, G., Daley, S. G., \& Rose, T. L. (2012). A research reader in Universal Design for Learning. Harvard Education Press.

Roberts, K. D., Park, H. J., Brown, S., \& Cook, B. (2011). Universal Design for Instruction in postsecondary education: A systematic review of empirically based articles. Journal of Postsecondary Education and Disability, 24(1), 5-15. https://eric.ed.gov/?id=EJ941728

Roddy, C., Amiet, D. L., Chung, J., Holt, C., Shaw, L., McKenzie, S., ... \& Mundy, M. E. (2017). Applying best practice online learning, teaching, and support to intensive online environments: An integrative review. Frontiers, 2(59), 1-10. https://doi.org/10.3389/feduc.2017.00059

Rogers-Shaw, C., Carr-Chellman, D. J., \& Choi, J. (2018). Universal design for learning: Guidelines for accessible online instruction. Adult Learning, 29(1), 20-31. https://doi.org/10.1177/1045159517735530
Rose, D. H., \& Meyer, A. (2000). Universal Design for Learning. Journal of Special Education Technology, 15(1), 67-70. https://doi.org/10.1177/016264340101600208

Smith, S. J., \& Bashman, J. D. (2014). Designing online learning opportunities for students with disabilities. Teaching Exceptional Children, 46(5), 127137. https://doi.org/10.1177/0040059914530102 